\title{
Relationship between Reflective Teaching and Teacher Autonomy among Iranian EFL Experienced and Novice Teachers
}

\author{
Parvinsadat Moslehi \\ English Department, Najafabad Branch, Islamic Azad University, Najafabad, Iran \\ Hadi Salehi (Corresponding author) \\ English Department, Najafabad Branch, Islamic Azad University, Najafabad, Iran \\ Email: hadisalehi1358@yahoo.com
}

Received: $21 / 04 / 2021$

Accepted: 10/07/2021

Published: 01/09/2021

Volume: 2 Issue: 5

How to cite this paper: Moslehi, P., \& Salehi, H. (2021). Relationship between Reflective Teaching and Teacher Autonomy among Iranian EFL Experienced and Novice Teachers. Journal of Practical Studies in Education, 2(5), 1-10

DOI: https://doi.org/10.46809/jpse.v2i5.28

Copyright (C) by author(s) and Global Talent Academy Ltd. This work is licensed under the Creative Commons Attribution International License (CC BY 4.0).

http://creativecommons.org/licenses/by/4.0/

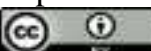

\begin{abstract}
The present study was an attempt to examine the relationship between reflective teaching and teacher autonomy among Iranian EFL experienced and novice teachers. The study was conducted with a sample of 100 EFL teachers that were selected by convenience sampling from language institutes in Isfahan, Iran. In order to neutralize the role of gender, as an intervening variable, an equal number of male and female participants were invited to take part in the study. Out of participants, 50 of them were experienced and 50 were novice teachers (those teachers who had fewer than five years and more than five years of teaching experience were considered novice and experienced participants). The participants were requested to fill out two questionnaires measuring reflective teaching and teacher autonomy. The descriptive statistics as well as inferential statistics were employed to analyze the data. The findings showed that there was a strong positive relationship between the experienced teachers' reflective teaching and their teacher autonomy and there was a moderate positive relationship between the novice teachers' reflective teaching and their teacher autonomy. The results of the present study will be useful for EFL teachers to have effective teaching. Obviously, reflective teaching would help teachers to foster their independence.
\end{abstract}

Keywords: Reflective Teaching, Teacher Autonomy, Experienced Teachers, Novice Teachers

\section{Introduction}

In recent years, educators have assigned a great deal of attention to the notion of reflection and the expansion of practice. Reflective teaching was first raised by Dewey (1933) who believed that "teachers are not just passive curriculum implementers, but they can also play an active role in curriculum design and educational reform" (p. 49). He suggested that teaching needs to be a process comprising the following components: Hypothesizing, investigation, reasoning, testing, and evaluation. Reflective action, is in essence "the dynamic, continuous and in-depth consideration of any belief or any form of expertise and knowledge by drawing on the grounds that reinforce it (Dewey, 1933, p. 9, cited in Jay \& Johnson, 2002, p. 74). These components will lead to adaptations and modification, if needed, leading to a teaching method which will take account of the class dynamics. 
Bartlett (1990) defined reflective teaching as a practice which the individual recalls, considers, and evaluates an experience often about a broader purpose. According to Akbari, Behzadpour and Dadvand (2010), scholars have recently begun to investigate the relationship or the effect of reflective teaching on other variables. In the Iranian context of ELT, Rezaeyan and Nikoopour (2013) investigated the relationship between the reflectivity of language teachers with Iranian students' achievement. The findings of the study showed a significant relationship between teachers' degree of reflectivity and students' achievement. In a study on the relationship between reflective teaching and teachers' burnout, Javadi and Khatib (2014) concluded that teachers' reflection was significantly and inversely related to their feeling of burnout.

Changes in the twentieth century in social sciences, psychology, philosophy, and political science have led to the growth of interest in autonomy as an educational goal (Finch, 2000). There has been a proliferation of terms regarding the concept of autonomy in the literature. The concept of autonomy as defined by Benard, (1995, p. 1) refers to "having a sense of one's own identity and an ability to act independently and to apply some control over one's environment, including a sense of task mastery, internal locus of control, and self-efficacy". A review of the literature related to teacher autonomy shows that there is not any consensus on the definition of autonomy. According to Sacks and Eisenstein (1976) autonomy is "self-rule," or "self-determination" (p. 7). In the field of psychology Piaget (as cited in Peck \& Havighurst, 1960, p. 17) defined autonomy as "ego-directed behavior, free from arbitrary outer pressures or irrational inner pressures".

According to Street (1988), teacher autonomy refers to "the independence teachers maintain in exercising discretion within their classrooms to make instructional decisions" (p. 4). Little (1995, p.176) defined teacher autonomy as the "teachers' capacity to engage in self-directed teaching." In the words of Smith (2000), teacher autonomy is "the ability to develop appropriate skills, knowledge and, attitudes for oneself as a teacher, in cooperation with others" (p.89). As Smith (2003, p. 1) stated, "definitions of teacher autonomy have tended to advocate one aspect to the exclusion of others, from teacher autonomy as a generalized 'right to freedom from control' to teachers' capacity to engage in self-directed teaching to teacher's autonomy as learners". Most recently, Jing Huang (2005, p. 4) defined teacher autonomy as "teachers' willingness, capacity and freedom to take control of their teaching and learning".

Several empirical studies have so far investigated the concept of teacher autonomy and other variables. In a study, Person and Moomaw (2005) found a close relationship between teacher sense of autonomy and job satisfaction and commitment. Pearson (1995) and Pearson and Hall (1993) examined the relationship between salary, workload, paperwork, and levels of stress. Veugelers, (2004) explored the impact of educational policies on teachers' responsibilities and accountability. Ingersoll (2003) showed how teacher control is affected by organizational factors.

Recently, the field of teaching in general and language teaching in particular has been subject to newly evolved theories of learning. As Akbari (2005), Kumaravadivelu (2001) and Pica (2000) asserted, language teaching, learning and teacher education have recently witnessed a great amount of change. Crandall (2000) stated that this change has been more of "a shift from the transmission, product-oriented theories to constructivist, and process-oriented theories of learning, teaching, and teacher learning" (pp. 34-35). Highlighting this view, Brown (2000) asserted that, constructivists posit that reality is constructed in social contexts. As a consequence of this new paradigm, the concept of learning and its process gained a new definition.

In the same context, Cunningham (2000) noted that "constructivism views learning as an active process where learners reflect upon their current and past knowledge and experiences to generate new ideas and concepts" (p. 2). Based on this recently emergent view of learning and because teachers have experienced learning at different stages of their lives and are always involved in an ongoing learning process, Crandall (2000) maintained that in the light of constructivism teachers are considered the main source of knowledge about teaching. Two of the primary concepts in the realm of teacher education and teacher learning which are in line with the constructivist views of learning are reflective teaching (Tabachnick \& Zeichner, 2002) and teacher autonomy (Pearson \& Moomaw, 2006).

According to Tabachnick and Zeichner (2002), reflective teaching is consistent with constructivist learning theories. It emphasizes the concept of reflection as a source of knowledge for teachers. Along the same lines, teacher autonomy lies in congruence with constructivism because it provides the teacher with more opportunities for exploration as a consequence of which efficient and effective learning can take place (Friedman, 1999; Crawford, 2001).

The main purpose of this study was to find the extent of the relationship between reflective teaching and teacher autonomy among Iranian EFL experienced and novice teachers. Therefore, this study aimed at addressing the following research questions:

RQ1: Is there any significant relationship between reflective teaching and teacher autonomy among Iranian EFL experienced teachers?

RQ2: Is there any significant relationship between reflective teaching and teacher autonomy among Iranian EFL novice teachers?

RQ3: Is there any significant difference between experienced and novice teachers considering the relationship between reflective teaching and teacher autonomy?

\section{Literature Review}

The following literature is about two variables related to reflective teaching and teacher autonomy and different types of reflection and their relationship with other variables. 


\subsection{Reflective Teaching}

Reflective teaching is an approach for teaching which requires "paying critical attention to the practical values and theories which inform everyday actions, by examining practice reflectively and reflexively" (Bolton, 2010, p. 22). In other words, it means a process of self-observation and self-evaluation of teachers during their teaching experience. Bartlett (1990) defined reflective teaching as a practice in which the individual recalls, considers, and evaluates an experience often about a broader purpose.

Reflective teaching has been a pivotal element in teaching field for more than 50 years. Dewey (1933) believed, "teachers are not just passive curriculum implementers, but they can also play an active role in curriculum design and educational reform" (p. 49). He also indicated that teaching should be a practice including a process of hypothesizing, investigation, reasoning, testing and evaluation, leading to modification and if necessary further investigation and this practice of teaching is what he considers as reflective teaching.

\subsection{Teacher Autonomy}

The first definition on teacher autonomy was given by Little (1995) as the "teachers' capacity to engage in self-directed teaching" (p.176). Later, Smith (2000) defined teacher autonomy as "the ability to develop appropriate skills, knowledge and attitudes for oneself as a teacher, in cooperation with others" ( $p .89)$. Teacher autonomy is an ability, or a skill by which teachers can develop their own teaching condition freely without any limitation (Javadi, 2014).

Kumaravadivel (2001) noted that teacher autonomy comprises teachers' competence and confidence to make them develop and apply a theory of their own, which works best in a particular educational context. Teacher autonomy is a crucial factor in teaching because of some distinctive features. Teacher autonomy is a right given to the teachers to decide and take responsibilities about selecting, or designing materials and strategies for their classrooms and to evaluate the outcomes and cooperate in finding solutions for the teaching problems in schools (Akbarpour Tehrani\& Wan Mansor, 2012). An autonomous teacher may feel more motivated when he/she can feel free to choose his/her own teaching materials, which gives him/her the required pleasure and satisfaction in his/her career.

\subsection{Studies Related to the Issue}

Some empirical studies conducted in Iranian and international contexts are reviewed here.

\subsubsection{Iranian Studies}

Javadi and Khatib (2014) studied the relationship between reflective teaching and teachers' burnout. Data were collected from 170 Iranian EFL teachers teaching at different Language institutes in Tehran. The participants received a five-point scale Likert -type questionnaire designed by Behzadpour (2007) and a 6-point Likert scale Maslach Burnout Inventory (Maslach, Jackson, \& Leiter, 1996). The qualitative data came from interviews with both genders in all 43 experience and age groups. The principle statistical procedures used for analyses of the data were Pearson-Product Moment and SPSS (version 16) program. Analyses of the achieved data confirmed that there is a significant negative relationship between teachers' reflection and their feeling of burnout. In other words, the more the teachers have reflection, the less they have feelings of burnout.

Mahmoodi and Ghaslani (2013) examined the relationship among teachers' burnout, emotional intelligence, and reflectivity using a sample of 125 Iranian EFL teachers in Kurdistan and Hamedan with the help of Maslach Burnout Inventory-Educators Survey, Teacher Reflectivity Questionnaire and Bar-OnEQ-IScale. They found that emotional intelligence and reflectivity negatively correlated with burnout, and they could both predict the level of burnout. There were also significant differences in teachers' level of emotional intelligence with respect to their teaching experience.

Recently, Javadi (2014) examined the relationship between feeling of burnout and teacher autonomy, as a professional development construct, among 143 EFL teachers in different private language teaching institutes in Iran. Data were collected using Maslach Burnout Inventory (Maslach, Jackson, \& Leiter, 1996) and Teaching Autonomy Scale developed by Pines and Hall (1993). Correlation analysis indicated that teacher autonomy was significantly and inversely related to their feeling of burnout. The Stepwise multiple regression also showed that the components of burnout, i.e., emotional exhaustion, depersonalization, and reduced personal accomplishment, were significant predictors of teacher autonomy.

In the Iranian context of ELT, Rezaeyan and Nikoopour (2013) investigated the relationship between reflectivity of language teachers with Iranian students' achievement. The findings of the study indicated a significant relationship between teachers' degree of reflectivity and students' achievement.

\subsubsection{International Studies}

Scholars have explored interconnections between reflective teaching and teacher self-efficacy. Regarding contributions of reflection to self-efficacy, Stallions, Murrill, and Earp (2012) found that reflection about unexpected challenges and crises at early career stages can help teachers develop a high sense of professional efficacy. Efficacy beliefs and self-confidence can also improve through teacher reflection facilitated by guided practices (Yeh, 2006), learning community behaviours (Kennedy \& Smith, 2013), microteaching (Donnelly \& Fitzmaurice, 2011), mentoring, peer coaching, and self-study (Sibbald, 2008). Finally, Milner and Woolfolk Hoy (2003) found that their research participant attributed her being stereotyped and isolated by her colleagues to her achievements (e.g., having a $\mathrm{PhD}$ ). This kind of reflection on her mastery experiences helped her to not only guard against negative effects of how she was treated but also improve her self-efficacy perceptions, a finding which has been theoretically argued for by Bandura (1997).

Regarding the impact of self-efficacy on reflection, Thoonen, Sleegers, Oort, Peetsma, and Geijsel (2011) observed that teachers' self-efficacy beliefs were the strongest motivational factor for explaining teachers' experimentation and reflection. 
Runhaar, Sanders, and Yang (2010) also found that teachers' perceived efficacy to deal with difficulties at work significantly accounted for their reflective thinking and asking for feedback from their managers, colleagues, or students. Similar findings have been observed regarding other types of participants, such as learners and employees. Kitsantas and Baylor (2001), for example, found that self-reflection about instructional planning encouraged learners to reconsider their self-efficacy beliefs and develop a more realistic understanding of their planning abilities. In the context of industry, selfefficacy was found to be the most important predictor of employees' critical reflective working behaviour, such as challenging group think and experimentation (van Woerkom, Nijhof \& Nieuwenhuis, 2002).

Skaalvik and Skaalvik (2014) examined the relationship among teacher self-efficacy, teacher autonomy, engagement, job satisfaction, and burnout. They used Teacher Self Efficacy Scale, the Teacher Autonomy Scale, the Utrecht Work Engagement Scale, the Teacher Job Satisfaction Scale, and the Maslach Burnout Inventory. Skaalvik and Skaalvik (2014) found that teacher autonomy and self-efficacy were predictors of burnout.

Garcia and Pintrich (1991) surveyed 365 college students from 4 institutions in the US to explore the effects of autonomy on motivation, use of learning strategies and performance in college classrooms. The results showed that autonomy was related to all the motivational constructs and most closely to intrinsic motivation. The findings of their study led them to conclude that autonomy fosters intrinsic motivation. The studies reported above revealed that either autonomy lead to motivation or vice versa.

\section{Method}

As it is stated above, the current research aimed mainly at investigating the relationship between reflective teaching and teacher autonomy among Iranian EFL experienced and novice teachers. In this section, a brief profile of the participants, the materials used, the procedures and measures applied for eliciting the necessary data will be presented.

\subsection{Participants}

The participants were 100 teachers at 5 language institutes in Isfahan, Iran. The range of their age was 25 to 47 . In order to neutralize the role of gender, as an intervening variable, equal number of male and female participants were invited to take part in the study. They were selected through convenience sampling and on the basis of their availability at the time of data collection (of course, if they were willing to participate. Those teachers who had fewer than 5 years and more than 5 years of teaching experience were considered novice and experienced participants, respectively.

\subsection{Design of the Study}

A descriptive research design was adopted because there was no manipulation in this research. In fact, the data on the two variables (i.e. reflective teaching and teacher autonomy) were collected using two questionnaires and no changes were made in the environment. Therefore, the answers to the research questions were discovered in the natural context of language learning.

\subsection{Instruments}

In this study, two questionnaires were used for measuring reflective teaching and teacher autonomy.

\subsection{Reflective Teaching Questionnaire}

This questionnaire used for measuring reflective teaching in this study was a reflective teaching questionnaire devised by Akbari, Behzadpour and Dadvand (2010). The questionnaire includes 29 items on a five-point Likert scale, consisting of five options of never, rarely, sometimes, often, and always. This questionnaire was chosen for the purposes of this study because it was developed for measuring teachers' reflection in the context of Iran and enjoys a high reliability of 0.90 as a measuring instrument for teacher reflectivity (Akbari, Behzadpour \& Dadvand, 2010).

\subsection{Teacher Autonomy Questionnaire}

The questionnaire used for assessing teacher autonomy level of the participants developed and validated by Moomaw (2005). This questionnaire has 18 items on a four-point Likert scale consisting of some statements which should be checked by participants with the four options of definitely true, more or less true, more or less false and definitely false. The questionnaire enjoys an acceptable level $(\mathrm{r}=0.81)$ of internal consistency (Moomaw, 2005).

\subsection{Procedure and Data Analysis}

At first, 100 teachers were selected through convenience sampling at 5 language institutes in Isfahan, Iran. In fact, the data on the two variables (i.e. reflective teaching and teacher autonomy) were collected through the use of two questionnaires and no changes were made in the environment. In this study, the EFL teachers under study were divided into two groups of novice and experienced teachers. Teachers with five years of teaching experience or less were considered novice EFL teachers and teachers with more than five years of teaching experience were considered experienced EFL teachers.

Therefore, the answers to the research questions were in the natural context of language learning. To meet the purpose of the study, the individuals who met the criteria mentioned in the Participants section were contacted by the researcher. A brief description was provided about the nature of the study and the purpose of data collection. After teachers' agreement to participate in the study, a package containing a copy of the two questionnaires measuring reflective teaching and teacher autonomy were distributed among them. The teachers were invited to take their time and answer the items in each of the questionnaires carefully. During the process of data collection, care was taken to consider the ethical issues of the research. For example, the teachers' participation in the research was voluntary. Besides, they were made sure of the secrecy of the information they provided. Also, they were informed that the collected data would be used for research purposes only. 
Participation in this study was voluntary and only those EFL teachers interested in being involved in the study completed the two questionnaires. The EFL teachers were asked to mark their responses with care and attention. In most cases, the EFL teachers could not fill in the questionnaires at that time because they were busy with their job, so they were asked to take the questionnaires home, answer the questions, and then return them to the principal of the institute. Then, the returned questionnaires were measured.

Descriptive statistical procedure was utilized in data analysis. To explore the research questions of the study as whether there is any significant relationship between reflective teaching and teacher autonomy level of Iranian EFL teachers, Pearson Correlation Coefficient formula which is a parametric test was utilized. Therefore, the research questions were answered through employing this test. To find the answer to this question and to find out the existence of a possible significant difference between these two relationships, Fisher's $r$-to- $z$ transformation formula was applied.

\section{Results}

The obtained results and findings are reported in this section.

\subsection{Preliminary Analyses}

Before running any correlational analyses, since one of the assumptions of Pearson correlation is the normality assumption, the information regarding the descriptive statistics and normality of the distributions belonging to the reflective teaching and autonomy of experienced and novice teachers is presented in this section.

Table1. Descriptive Statistics for Experienced and Novice Teachers' Reflective Teaching \& Autonomy

\begin{tabular}{ccccccc}
\hline Teachers & Questionnaires & $N$ & Mean & Std. Deviation & Skewness & Kurtosis \\
\hline \multirow{2}{*}{ Experienced } & Reflective Teaching & 50 & 103.28 & 11.72 & .462 & -.20 \\
\cline { 2 - 7 } & Autonomy & 50 & 54.96 & 4.19 & -.58 & -.72 \\
\hline \multirow{2}{*}{ Novice } & Reflective Teaching & 50 & 100.18 & 8.49 & -.44 & .23 \\
\cline { 2 - 7 } & Autonomy & 50 & 50.30 & 10.60 & -.33 & -.26 \\
\hline
\end{tabular}

The information presented in Table 1 shows the number of participants in the experienced and novice teachers' groups, their mean scores, standard deviations, skewness, and kurtosis values on the reflective teaching and autonomy questionnaires. For experienced teachers, the mean scores of 103.28 and 54.96 were obtained for reflective teaching and autonomy, respectively. The skewness and kurtosis values indicate that these distributions were normal as the values were smaller than \pm 2 . Regarding novice teachers, the reflective teaching mean score equaled 100.18 and their autonomy mean score was found to be 50.30. These two distributions were also apparently normal as their skewness and kurtosis values were lower than \pm 2 . However, a more robust test of normality was run as well, the results of which are presented in Table 2.

Table2. Results for the Test of Normality

\begin{tabular}{|c|c|c|c|c|c|c|c|}
\hline \multirow{2}{*}{ Teachers } & \multirow{2}{*}{ Questionnaires } & \multicolumn{3}{|c|}{ Kolmogorov-Smirnov } & \multicolumn{3}{|c|}{ Shapiro-Wilk } \\
\hline & & Statistic & $d f$ & Sig. & Statistic & $D f$ & Sig. \\
\hline \multirow{2}{*}{ Experienced } & Reflective Teaching & .12 & 50 & .06 & .96 & 50 & .14 \\
\hline & Autonomy & .11 & 50 & .10 & .94 & 50 & .26 \\
\hline \multirow{2}{*}{ Novice } & Reflective Teaching & .11 & 50 & .07 & .97 & 50 & .46 \\
\hline & Autonomy & .12 & 50 & .06 & .94 & 50 & .22 \\
\hline
\end{tabular}

The results for the Kolmogorov-Smirnov test of normality are presented in Table 2. Under the Sig. column in the Kolmogorov-Smirnov section of the test, the $p$ value are listed. If the $p$ values are greater than the .05 level of significance, this means that the assumption of normality was not violated. As all these $p$ values were found to be greater than .05 , it could 
be construed that the distributions for both experienced and novice teachers' reflective teaching and autonomy were normal. It is thus safe now to proceed with the correlational analyses presented in what follows.

\subsection{Reflective Teaching \& Autonomy: Experienced Teachers}

As stated above, the first objective of the study was to determine whether there was any significant relationship between reflective teaching and teacher autonomy among Iranian EFL experienced teachers. To achieve this aim, Pearson correlation was conducted on the reflective teaching and teacher autonomy scores of the experienced teachers participating in this study. The results of this correlational analysis are illustrated in Table 3.

Table3. Pearson Correlation for the Relationship between Reflective Teaching and Autonomy of Experienced Teachers

\begin{tabular}{|c|c|c|c|}
\hline & & Reflective Teaching & Teacher Autonomy \\
\hline \multirow{3}{*}{ Reflective Teaching } & Pearson Correlation & 1 & $.57^{* *}$ \\
\hline & Sig. (2-tailed) & & .00 \\
\hline & $N$ & 50 & 50 \\
\hline \multirow{3}{*}{ Teacher Autonomy } & Pearson Correlation & $.57^{* *}$ & 1 \\
\hline & Sig. (2-tailed) & .00 & \\
\hline & $N$ & 50 & 50 \\
\hline
\end{tabular}

Table 3 shows that there was a strong positive relationship between the experienced teachers' reflective teaching and teacher autonomy since Pearson correlation coefficient was found to be .57. Based on Cohen (1988, cited in Pallant, 2010), a relationship is weak if it falls between .0 and \pm .30 ; it is moderate if it ranges between \pm .30 and \pm .50 ; and it is strong provided that it exceeds \pm .50 . In this case, the relationship outstripped .50, and was thus found to be strong. This strong correlation between the experienced teachers' reflective teaching and teacher autonomy was statistically significant at $p<.01$ since the $p$ value turned out to be .00 . Figure 1 also shows this relationship graphically:

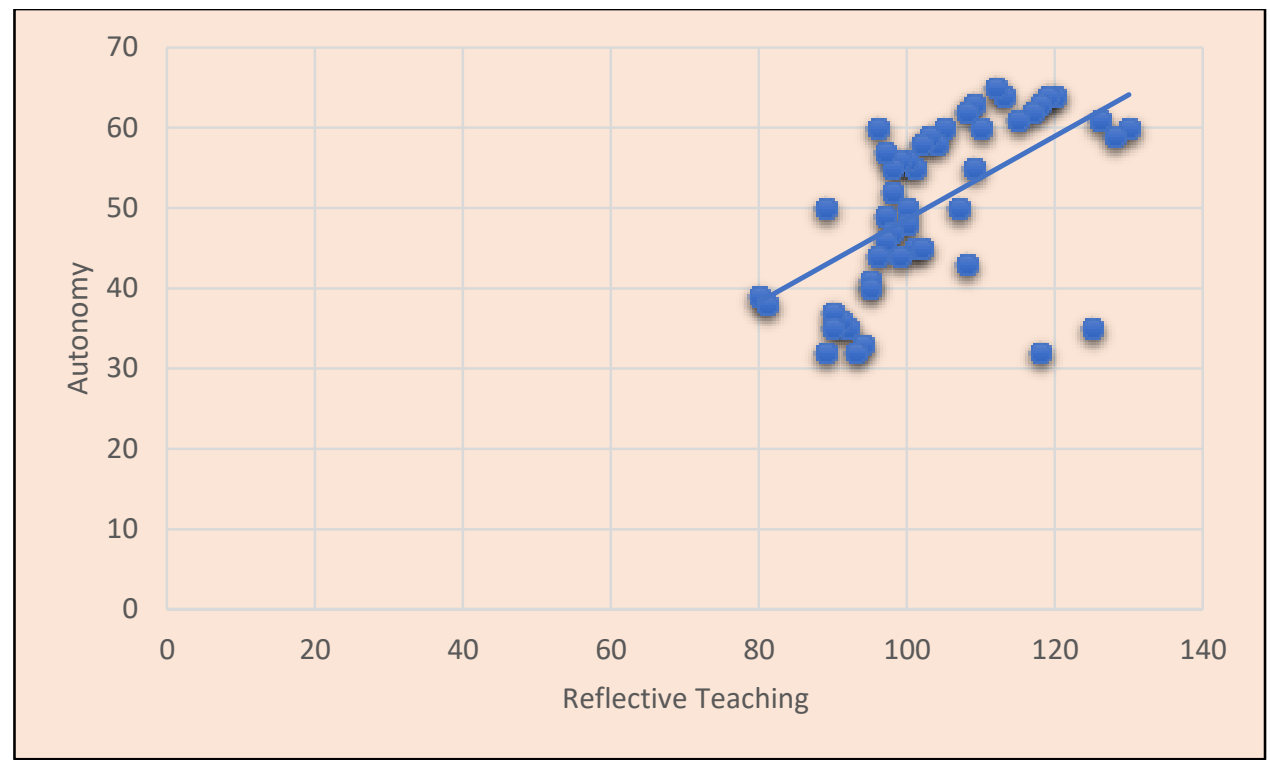

Figure 1. Relationship between experienced teachers' reflective teaching and teacher autonomy 
This figure also shows a positive relationship between the experienced teachers' reflective teaching and their autonomy since the hypothetical trend line delineates a sharp rise towards the upper right-hand corner of the graph.

4.3. Reflective Teaching and Autonomy: Novice Teachers

The second objective of the study was to determine whether there was any significant relationship between reflective teaching and teacher autonomy among Iranian EFL novice teachers. To fulfil this objective, another Pearson correlation was conducted using the reflective teaching and the teacher autonomy scores of the novice teachers. The results for this analysis are demonstrated in Table 4.

Table4. Pearson Correlation for the Relationship between Reflective Teaching and Autonomy of Novice Teachers

Reflective Teaching Teacher Autonomy

\begin{tabular}{llll}
\hline & & 1 & $.44^{* *}$ \\
\cline { 2 - 4 } Reflective Teaching & Sig. (2-tailed) & & .00 \\
\cline { 2 - 4 } & $N$ & 50 & 50 \\
\hline & Pearson Correlation & $.44^{* *}$ & 1 \\
\cline { 2 - 4 } Teacher Autonomy & Sig. (2-tailed) & .00 & \\
\cline { 2 - 4 } & $N$ & 50 & 50 \\
\hline ** Correlation is significant at the .01 level (2-tailed). & & \\
\hline
\end{tabular}

Table 4 shows that there was a moderate positive relationship between the novice teachers' reflective teaching and their teacher autonomy since Pearson correlation coefficient was found to be .44. This strong correlation between the novice teachers' reflective teaching and teacher autonomy was statistically significant at $p<.01$ since the $p$ value turned out to be .00 . Figure 2 also shows a graphic representation of this relationship:

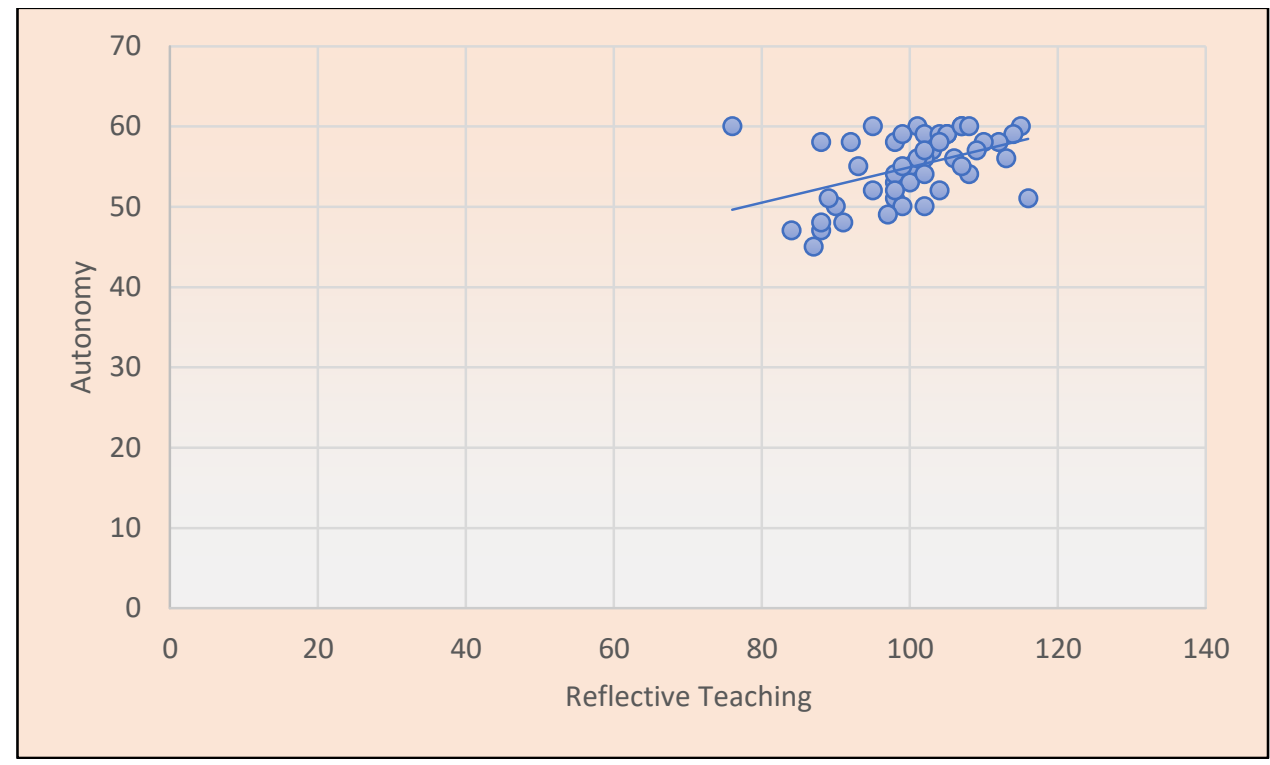

Figure 2. Relationship between novice teachers' reflective teaching and teacher autonomy

Figure 2 demonstrates a moderate positive relationship between the novice teachers' reflective teaching and their teacher autonomy as the trend line demonstrated a rather sharp rise from the lower left-hand side towards the upper right-hand corner of the graph.

4.4. Comparing the Relationships: Experienced vs. Novice Teachers 
The third objective of the present study was to determine whether there was any significant difference between experienced and novice teachers considering the relationship between reflective teaching and teacher autonomy. To find the answer to this question and to find out the existence of a possible significant difference between these two relationships, Fisher's $r$-to- $z$ transformation formula was applied (the analysis was made through the online Fisher's $r$-to- $z$ transformation formula available at http://vassarstats.net/rdiff.html). The value of $\mathrm{z}$ obtained in this analysis was found to be .85 , and the $p$ (two-tailed) equaled .39. Consequently, it could be concluded that the difference between the two correlation coefficients was not a statistically significant one.

\section{Discussion}

The results obtained from the analysis of the tests highlighted the relationship between reflective teaching and teacher autonomy among Iranian EFL experienced and novice teachers.

\subsection{Addressing the First Research Question}

The first research question of this research focused on the relationship between reflective teaching and teacher autonomy among Iranian EFL experienced teachers. The results of the study revealed that there is a strong positive relationship between the experienced teachers' reflective teaching and teacher autonomy. It can be claimed that teachers have reflection and concern for developing their teaching skills, the more they are autonomous.

In the Iranian context of ELT, Rezaeyan and Nikoopour (2013) investigated the relationship between the reflectivity of language teachers with Iranian students' achievement. The findings of the study indicated a significant relationship between teachers' degree of reflectivity and students' achievement.

\subsection{Addressing the Second Research Question}

Based on the second research question of the study concerning the relationship between the novice teachers' reflective teaching and their teacher autonomy, there was a moderate positive relationship between the novice teachers' reflective teaching and their teacher autonomy since Pearson correlation coefficient was found to be .44. This strong correlation between the novice teachers' reflective teaching and teacher autonomy was statistically significant at $p<.01$ since the $p$ value turned out to be .00 .

With respect to expert and novice teachers' beliefs and practices, Berko and Livingston (1989) concluded that expert teachers are more autonomous in decision making while novice teachers tend to believe in procedures, rules and curriculum guidelines. Moreover, they concluded that expert teachers show more flexibility to contextual variations such as student responses, disruptions, and available resources. In contrast, novice teachers are less able to anticipate class events and therefore are less flexible. Kagan and Tippins (1992) argued that novice teachers spend much energy and time on planning lessons which are more detailed and elaborate.

\subsection{Addressing the Third Research Question}

The third research objective of the present study was to determine whether there was any significant difference between experienced and novice teachers considering the relationship between reflective teaching and teacher autonomy. To find the answer to this question and to find out the existence of a possible significant difference between these two relationships, Fisher's $r$-to- $z$ transformation formula was applied. Consequently, it could be concluded that the difference between the two correlation coefficients was not a statistically significant one.

\section{Conclusion}

The findings of such studies can help novice teachers recognize what expert teachers think and know, how they know what they know, and how they use what they know in their job. This could help novice teachers prepare themselves better for their classes and help teacher educators make more informed decisions in training teachers. The higher degree of teachers' reflection leads to the higher degree of teacher's autonomy. In other words, the more the teachers have reflection and concern for developing their teaching skills, the more they are autonomous.

Positive use of reflective teaching principles as a pedagogical tool can help teachers to improve their practice and be more efficacious in their classroom. Teachers should give more attention to what happens in their classroom before, after, and even at the moment of teaching. Their considerations, interpretations, deliberations and thoughts about their teaching experience can affect and improve their practice greatly and pave the way for learner's improvements.

With regard to the results of the study, Iranian EFL expert teachers had higher levels of procedural knowledge than Iranian EFL novice teachers. It could be concluded that Iranian EFL expert teachers were ahead of the novice ones in many aspects in this research. We tried to clarify the main and factors that Iranian EFL teachers need to promote in themselves using novice and expert teachers' knowledge, experiences, problems and solutions for these problems.

The findings of this study provide reasonable support for suggesting that EFL teachers should invest in promoting their knowledge. They should also delve into the models of reflective teaching and enhance their familiarity with the ways of using which they can function as reflective teachers. According to Dewey (1933), the key attitudes that are essential for engaging in a reflective teaching practice. This finding highlights the importance of reflective teaching in teacher education programs even further. 
As a final word, as stated earlier, the results of the present study indicate that for experienced teachers, there is a strong positive relationship between reflective teaching and teacher autonomy and there is a moderate positive relationship between novice teachers' reflective teaching and their teacher autonomy and the difference between the experienced and novice teachers in terms of the relationship between their reflective teaching and autonomy did not reach statistical significance.

This study has some implications: for EFL experienced and novice teachers and teacher trainers to inject reflection in their teaching process, for the providers and developers of educational materials and language institute owners, also for syllabus designers to include reflection in the syllabus of pedagogy as to pay more attention to the important concepts of reflectivity and autonomy. The findings of this study also can be fruitful for teacher educators, institute managers, and government officials to raise language teachers' awareness of the dire importance of reflecting on their teaching experiences in order to understand the phenomenon of language teaching and learning from a deeper perspective and come to a better understanding of the emotions they experience throughout their teaching career.

This study, like many research studies, has suffered from a couple of limitations. The first limitation of the study was the sample size. Since the current study used a questionnaire among the limited number of participants, further studies with larger samples are required to guarantee findings. The second limitation was that the participants in this study were selected only from language institutes in Isfahan. The third limitation of this study was that it used only the questionnaire as instrument but the interview protocol can also be used to consolidate the results. The fourth limitation was finding the participants in this difficult Corona situation.

\section{References}

Akbari, R. (2005). Recent developments in foreign language teaching. ROSHD FLT, 20, (76), 25-32.

Akbari, R., Behzadpoor, F., \& Dadvand, B. (2010). Development of English language teaching reflection inventory. System, 38, 211-227.

Bandura, A. (1997). Self-efficacy in Changing Societies. Cambridge University Press.

Bartlett, L. (1990). Teacher development through reflective teaching. In J.C. Richards and D. Nunan (Eds), Second Language Teacher Education (pp. 2002-214). New York: Cambridge University Press.

Behzadpour, F. (2007). Developing a measuring instrument for reflective teaching (Unpublished master's thesis). Tarbiat Modares University, Tehran, Iran.

Bolton, G. (2010). Reflective practice, writing and professional development (3rd ed.). California: SAGE publications.

Borko, H., \& Linvingstone, C. (1989). Cognition and improvisation: Differences in mathematics instruction by expert and novice teachers. American Educational Research Journal, 26(4),473-498.

Brown, H. D. (2000). Principles of Language Learning and Teaching. New York: Longman.

Crandall, J. A. (2000). Language teacher education. Annual Review of Applied Linguistics, 20, 34-55.

Crawford, J.R. (2001). Teacher autonomy and accountability in charter schools. Education and Urban Society, 33(2), 186200 .

Cunningham, F. M. (2000). Reflecting Teaching Practice in Adult ESL Settings. ERIC Digest, 1-7.

Dewey, J. (1933). How we think: A restatement of the relation of reflective thinking to the educative process. New York D.C: Heath and company.

Dewey, J. (1933/ 1993). How We Think: A Re-Statement of the Relation of Reflective Thinking to the Education Process. DC. Health, \& Co., Boston.

Donnelly, R., \& Fitzmaurice, M. (2011). Towards productive reflective practice in microteaching, Innovations in Education and Teaching International, 48(3), 335-346, https://doi.org/10.1080/14703297.2011.593709

Finch, A.E. \& Hyun, T. D. (2000f). The Way Ahead: Teachers' Resource Book. Seoul: Hakmunsa Press.

Finch, A.E. \& Hyun, T.D. (2000). Now you're talking! Seoul: Hakmunsa Press.

Friedman, R. (1999). Teacher-perceived work autonomy: The concept and its measurement. Occupations, 12(1), 59-76.

Huang, J. (2005). Metacognition training in the Chinese university Classroom: An action research study. Educational Action Research, 13(3), 413-434.

Ingersoll, R. M. (2003). Who controls teachers' work? Power and accountability in America's schools. Cambridge, MA: Harvard University Press.

Javadi, F. (2014). On the relationship between teacher autonomy and feeling of burnout among Iranian EFL teachers. Procedia-Social and Behavioral Sciences, 98, 770-774.

Javadi, F., \& Khatib.M, (2014). On the relationship between reflective teaching and teachers' burnout, International Journal of Research Studies in Language Learning, 3(4).

Jay, J. K., \& Johnson, K. L. (2002). Capturing complexity: a typology of reflective practice for teacher education. Teaching and Teacher Education, 18, 73-85.

Kagan, D. M. \& Tippins, D. J. (1992). The evolution of functional lesson plans among twelve elementary and secondary student teachers. The Elementary School Journal, 92, 477-489.

Kennedy, S. Y., \& Smith, J. B. (2013). The relationship between school collective reflective practice and teacher physiological efficacy sources. Teaching and Teacher Education, 29, 132-143. http://dx.doi.org/10.1016/j.tate.2012.09.003 
Kitsantas, A., \& Baylor, A. (2001). The impact of the instructional planning self-reflective tool on pre-service teacher performance, disposition, and self-efficacy beliefs regarding systematic instructional planning. Educational Technology Research and Development, 49, 97-106. http://dx.doi.org/10.1007/BF02504949

Kumaravadivelu, B. (2001). Toward a post-method pedagogy. TESOL Quarterly, 35(4), 537-560.

Little, D. (1995). Learning as dialogue the dependence of learner autonomy on teacher autonomy. System, 23(2), $175-181$.

Mahmoodi, M. H., \& Ghaslani, R. (2013). Relationship among Iranian EFL teachers' emotional intelligence, reflectivity and burnout. Iranian Journal of Applied Language Studies, 6(1), 90-116.

Maslach,C., Jackson, S.,\& Leiter,M. P. (1996). Maslach Burnout Inventory (3rd ed.). Palo Alto,CA: Consulting Psychologists Press.

Milner, H. R., \& Hoy, A. W. (2003). A case study of an African American Teacher's self-efficacy, stereotype threat, and persistence. Teaching and Teacher Education, 19, 263-276. http://dx.doi.org/10.1016/S0742-051X(02)00099-9

Pearson, L. C., \& Hall, B. C. (1993). Initial construct validation of the teaching Autonomy scale. The Journal of Educational Research, 86(3), 172-177.

Pearson, L. C., \& Moomaw, W. (2005). The relationship between autonomy and stress, work satisfaction, empowerment, and professionalism. Educational Research Quarterly, 29(1), 37-53.515). Heinle \& Heinle, Boston, MA.

Pearson, L. C., \& Moomaw, W. (2006). Continuing validation of the Teaching Autonomy. Educational and Psychological Measurement, 52(3), 258-273.

Peck, R. F., \& Havighurst, R. J. (1960). The psychology of character development. New York: John Wiley and Sons.

Pica, T. (2000). Tradition and transition in English language teaching methodology. System, 28(1), 39-47.

Pines, A. M. (1993). Burnout: An existential perspective. In W. Schaufeli, C. Maslach, \& T. Marek (Eds.), Professional Burnout: Recent Developments in Theory and Research (pp.33-51). Philadelphia, PA: Taylor and Francis.

Rezaeyan, M., \& Nikoopour,J. (2013). The Relationship between Reflectivity of Foreign Language Teachers with Iranian Students' Achievement. Journal of Language Sciences \& Linguistics. 1 (1), 9-02,

Runhaar, P., Sanders, K., \& Yang, H. (2010). Stimulating teachers' reflection and feedback asking: An interplay of selfefficacy, learning goal orientation, and transformational leadership. Teaching and teacher education, 26(5), 11541161. Sacks, S. R., \& Eisenstein, H. (1976). Feminism and psychological autonomy: A study in Scale. The Journal of Educational Research, 100(1), 44- 51.

Sibbald, T. M. (2008). The connection between teacher self-efficacy and reflective practice (Doctoral dissertation, University of Toronto).

Skaalvik, E. M., \& Skaalvik, S. (2014). Teacher self-efficacy and perceived autonomy: Relations with teacher engagement, job satisfaction, and emotional exhaustion Psychological Reports: Employment Psychology \& Marketing, 114(1), 6877.

Smith, R. C. (2000). Starting with ourselves: Teacher-learner autonomy in language learning. In B. Sinclair, I. McGrath \& T. Lamb (Eds.), Learner Autonomy, Teacher

Smith, R. C. (2003). Teacher education for teacher-learner autonomy. Centre for English Language Teacher Education (CELTE), University of Warwick, UK.

Stallions, M., Murrill, L., \& Earp, L. (2012). Don't Quit Now!: Crisis, Reflection, Growth, and Renewal for Early Career Teachers. Kappa Delta Pi Record, 48, 123-128.http://dx.doi.org/10.1080/00228958.2012.707504

Street, M. S. (1988). An investigation of the relationships among supervisory expertise of the principal, teacher autonomy, and environmental robustness of the school. Doctoral dissertation, Louisiana State.

Tabachnik, R., \& Zeichner, K. (2002). Reflections on Reflective Teaching. In A. Pollard. (Ed.), Readings for Reflective Teaching (pp. 13-16). London: Continuum.

Tehrani, Akbarpour. A., \& Wan Mansor, F. A. W. (2012). The Influence of 'Teacher Autonomy in Obtaining Knowledge'on 'Class Practice'. Procedia-Social and Behavioral Sciences, 66, 544-554.

Thoonen, E. E. J., Sleegers, P. J. C., Oort, F. J., Peetsma, T. T. D., \& Geijsel, F. P. (2011). How to Improve Teaching Practices: The Role of Teacher Motivation, Organizational Factors, and Leadership Practices. Educational Administration Quarterly, 47, 496-536.http://dx.doi.org/10.1177/0013161X11400185

Van Woerkom, M., Nijhof, W. J., \& Nieuwenhuis, L. F. (2002). Critical reflective working behaviour: A survey research. Journal of European Industrial Training, 26, 375-383.http://dx.doi.org/10.1108/03090590210444955

Veugelers, W. (2007). Creating critical-democratic citizenship in education: empowering humanity and democracy in Dutch Education. Compare: A Journal of Comparative Education. $37(1), \quad 105-119$. http://dx.doi.org/10.1080/03057920601061893

Yeh, Y. (2006). The interactive effects of personal traits and guided practices on preservice teachers' changes in personal teaching efficacy. British Journal of Educational Technology, 37, 513-526. http://dx.doi.org/10.1111/j.14678535.2006.00550.x 